\title{
К ВОПРОСУ РАЗВИТОСТИ ВИРТУАЛЬНОЙ МОБИЛЬНОСТИ УЧЕБНОГО ПРОЦЕССА КАК КЛЮЧЕВОГО ФАКТОРА ПОВЫШЕНИЯ КОНКУРЕНТОСПОСОБНОСТИ ВЫСШИХ УЧЕБНЫХ ЗАВЕДЕНИЙ В РОССИЙСКОЙ ФЕДЕРАЦИИ
}

\author{
(c) 2019 Долгова Елена Геннадьевна \\ кандидат филологических наук, доцент, кафедра иностранных языков № 3 \\ Российский экономический университет им. Г.В. Плеханова, Россия, Москва \\ E-mail: artzishevich@inbox.ru \\ (c) 2019 Юткина Светлана Владимировна \\ кандидат филологических наук, доцент, кафедра иностранных языков № 3 \\ Российский экономический университет им. Г.В. Плеханова, Россия, Москва \\ E-mail: Yutkina.SV@rea.ru \\ (c) 2019 Адасова Яна Борисовна \\ преподаватель кафедры иностранных языков № 3 \\ Российский экономический университет им. Г.В. Плеханова, Россия, Москва \\ Email: adasova_yana@rambler.ru \\ (c) 2019 Марциновская Виктория Александровна \\ старший преподаватель кафедры иностранных языков № 3 \\ Российский экономический университет им. Г.В. Плеханова, Россия, Москва \\ Email: vitam1981@mail.ru
}

В статье авторов рассматривается вопрос развитости виртуальной мобильности учебного процесса, как ключевого фактора повышения конкурентоспособности высших учебных заведений в Российской Федерации. Объектом исследования выступила конкурентоспособность высших учебных заведений в Российской Федерации, а предметом фактор повышения их конкурентоспособности в аспекте развитости виртуальной мобильности учебного процесса. Теоретическое и методологическое значение исследования заключены в расширении представлений об уровне конкурентоспособности высших учебных заведений в рамках ценой и неценовой проекций. Практическое значение исследования определяется выявлением возможных вариантов развития виртуальной мобильности учебного процесса в высших учебных заведениях Российской Федерации.

Ключевые слова: Развитость, виртуальная реальность, мобильность, учебный процесс, ключевой фактор, повышение, конкурентоспособность, высшее учебное заведение, Российская Федерация.

В условиях модернизации образовательного процесса в высших учебных заведениях Российской Федерации [4, с. 75] на фоне инновационных преобразований в мировой экономической системе [7] в аспекте оптимизации доходной и расходной базы, значительную актуальность приобретают вопросы эффективного конкурентного соперничества функционирующих на рынке объектов [2, с. 139]. Указанный факт подтверждается, в том числе, исследованиями компании Эксперт РА [10] по уровню конкурентоспособности высших учебных заведений в Российской Федерации (рис. 1).

Данные рисунка 1 свидетельствуют о том, что за анализируемый период времени средний относительный уровень конкурентоспособности высших учебных заведений Российской Федерации по всем возможным параметрам снизился более чем в 1,3 раза. Указанное изменение, как можно увидеть из рисунка 1 , носило практически полиномиальный характер второго порядка с уровнем достоверности близким к 0,99 единицы. Следовательно, при сохранении значений параметров, приведших к возникновению сложившейся ситуации, к началу 2020 года уровень конкурентоспособности высших учебных заведений в Российской Федерации может снизиться ниже отметки в 50 процентов из 100 возмож- 


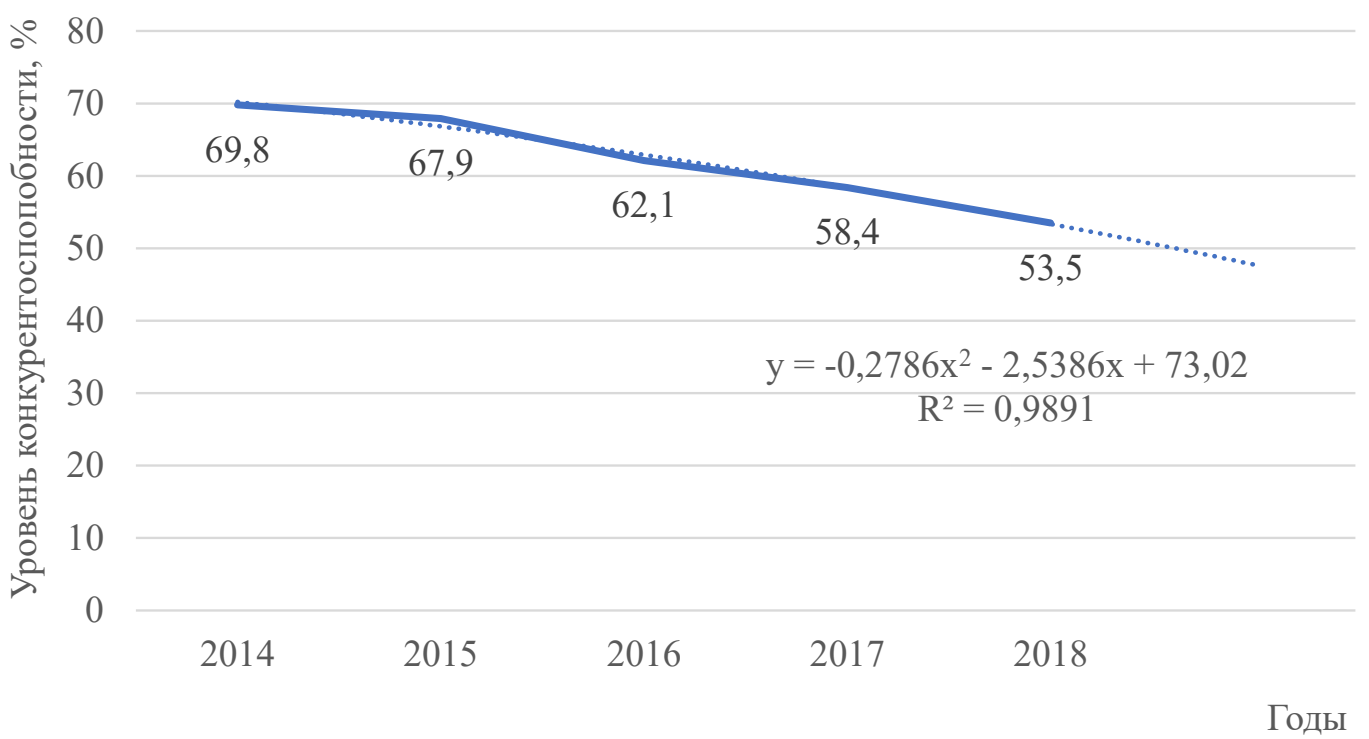

Puc. 1. Уровень конкурентоспособности высших учебных заведений Российской Федерации в 2014-2018 годах

ных. В долгосрочной перспективе, при условии сохранения текущей негативной демографической ситуации, это может привести к значительному изменению всей системы высшего образования.

В целях данной публикации была предпринята попытка дифференциации влияния ценовых и неценовых факторов на уровень конкурентоспособности [3, с. 2915] высших учебных заведений Российской Федерации в 2014-2018 годах. Полученные авторами результаты отражены в таблице 1.

Из таблицы 1 можно увидеть следующее:

- за анализируемый период времени влияние ценовых факторов на уровень конкурен- тоспособности высших учебных заведений Российской Федерации без учета прогнозного периода снизился в 1,38 раза (с 39,60 процентов до 28,60 процентов);

- за анализируемый период времени влияние неценовых факторов на уровень конкурентоспособности высших учебных заведений Российской Федерации без учета прогнозного периода снизился в 1,21 раза (с 30,20 процентов до 24,90 процентов);

- в целом за анализируемый период имеет место значительное прямое превалирование доли ценовой составляющей при формировании уровня конкурентоспособности высших учебных заведений над неценовой, что свиде-

Таблица 1. Влияние ценовых и неценовых факторов на уровень конкурентоспособности высших учебных заведений Российской Федерации в 2014-2018 годах

\begin{tabular}{|c|c|c|c|c|c|}
\hline Годы & Уровень, \% & $\begin{array}{c}\text { Ценовая } \\
\text { составляющая, \% }\end{array}$ & Доля, ед. & $\begin{array}{c}\text { Неценовая } \\
\text { составляющая, \% }\end{array}$ & Доля, ед. \\
\hline 2014 & 69,80 & 39,60 & 0,57 & 30,20 & 0,43 \\
\hline 2015 & 67,90 & 37,80 & 0,56 & 30,10 & 0,44 \\
\hline 2016 & 62,10 & 35,60 & 0,57 & 26,50 & 0,43 \\
\hline 2017 & 58,40 & 31,90 & 0,55 & 26,50 & 0,45 \\
\hline 2018 & 53,50 & 28,60 & 0,53 & 24,90 & 0,47 \\
\hline 2019 (прогноз) & 48,60 & 26,30 & 0,54 & 22,30 & 0,46 \\
\hline Среднее & 60,05 & 33,30 & 0,55 & 26,75 & 0,45 \\
\hline \multicolumn{5}{|c|}{ Контрольная сумма } & \multicolumn{3}{|c|}{} \\
\hline
\end{tabular}

Примечания: среди высших учебных заведений в Российской Федерации анализу подверглась лишь их аккредитованная часть по актуальным данным на соответствующий период времени; распределение ценовых и неценовых массивов данных осуществлялось с использованием специализированных программных продуктов с нейросетевым инструментарием. 
Таблица 2. Основные варианты развития виртуальной мобильности учебного процесса как ключевого фактора повышения конкурентоспособности высших учебных заведений Российской Федерации на 2019-2022 годы

\begin{tabular}{|c|c|c|}
\hline Вариант & Возможный пример & Вид изменения \\
\hline $\begin{array}{l}\text { замена прослушивания лекцион- } \\
\text { ного материала в очной форме на } \\
\text { интерактивную }\end{array}$ & $\begin{array}{l}\text { например, предоставление лекций } \\
\text { в электронном формате с инте- } \\
\text { рактивной интеграцией медиа } \\
\text { компонентов }\end{array}$ & $\begin{array}{l}\text { полностью (превалирующая пози- } \\
\text { ция) или частично }\end{array}$ \\
\hline $\begin{array}{l}\text { замена проведения семинарских } \\
\text { занятий в очной форме на инте- } \\
\text { рактивную }\end{array}$ & $\begin{array}{l}\text { например, проведение занятий в } \\
\text { интерактивной форме по уда- } \\
\text { ленным каналам связи, включая } \\
\text { видеоданные }\end{array}$ & $\begin{array}{l}\text { полностью или частично (превали- } \\
\text { рующая позиция) }\end{array}$ \\
\hline $\begin{array}{l}\text { замена проведения контрольных } \\
\text { точек в очной форме на интерак- } \\
\text { тивную }\end{array}$ & $\begin{array}{l}\text { например, проведение контроль- } \\
\text { ных работ в форме интерактивного } \\
\text { тестирования в личном кабинете } \\
\text { студента с последующим разме- } \\
\text { щением их результатов в режиме } \\
\text { онлайн }\end{array}$ & $\begin{array}{l}\text { полностью или частично (превали- } \\
\text { рующая позиция) }\end{array}$ \\
\hline $\begin{array}{l}\text { замена проверки работ в рамках } \\
\text { контрольных точек в очной форме } \\
\text { на интерактивную }\end{array}$ & $\begin{array}{l}\text { например, осуществление центра- } \\
\text { лизованной проверки контроль- } \\
\text { ных работ в личном кабинете } \\
\text { преподавателя }\end{array}$ & $\begin{array}{l}\text { полностью или частично (превали- } \\
\text { рующая позиция) }\end{array}$ \\
\hline $\begin{array}{l}\text { замена проведения экзаменаци- } \\
\text { онных работ в очной форме на } \\
\text { интерактивную }\end{array}$ & $\begin{array}{l}\text { например, проведение экзамена } \\
\text { в форме онлайн интервью, совме- } \\
\text { щенного с тестированием на сайте } \\
\text { высшего учебного заведения в } \\
\text { личном кабинете студента }\end{array}$ & $\begin{array}{l}\text { полностью или частично (превали- } \\
\text { рующая позиция) }\end{array}$ \\
\hline $\begin{array}{l}\text { прочие варианты развития вирту- } \\
\text { альной мобильности обучения }\end{array}$ & $\begin{array}{l}\text { например, проведение виртуаль- } \\
\text { ных конференций и прочее }\end{array}$ & полностью или частично \\
\hline
\end{tabular}

тельствует о доминировании финансовых предпочтений клиентов";

- указанное соотношение с большой долей вероятности сохранится и в прогнозном периоде, где доля ценовых факторов влияющих на конкурентоспособность высших учебных заведений может составить 0,54 единицы против 0,46 единиц для неценовых;

- среднее значение анализируемой величины с учетом прогнозного периода составило 60,05 процента, в том числе 33,30 процентов для ценовых факторов и 26,75 процентов для неценовых факторов, следовательно в будущем может идти речь в том числе об уделении внимания оптимизации стоимости образовательного процесса в целях повышения его конкурентоспособности.

По мнению аналитиков консалтинговой компании Ernst\&Young [9] одним из наиболее перспективных вариантов повышения конкурентоспособности [5] высших учебных заведений в Российской Федерации, как в аспекте оптимизации ценовой (стоимость обучения в высшем учебном заведении), так и неценовой (уровень профессионализма персонала, репутация высшего учебного заведения [8], качество получаемых знаний и прочее) составляющих является активизация развития виртуальной мобильности учебного процесса [1, с. 9].

Основные варианты реализации данной инициативы высшими учебными заведениями Российской Федерации на ближайшие три года, по мнению авторов, сведены в таблицу 2.

Из таблицы 2 видно, что применение обозначенных вариантов целесообразно внедрять в учебный процесс** в большей мере частично (превалирующая позиция по данном варианту имеет место у большинства позиций, требующих непосредственного контакта с преподавателем).

Внедрение указанных инициатив, по мнению авторов, позволит существенно снизить уровень затрат высших учебных заведений в Российской Федерации, одновременно увеличив уровень их конкурентоспособности.

Возможные варианты уровня конкуренто-

" В Российской Федерации в 2018 году при получении высшего профессионального образования к помощи финансовых институтов (банков) [6, с. 232] в той или иной мере обращался каждый второй студент.

** Примечание: применение обозначенных вариантов актуально как для очной, так и заочной форм обучения. 


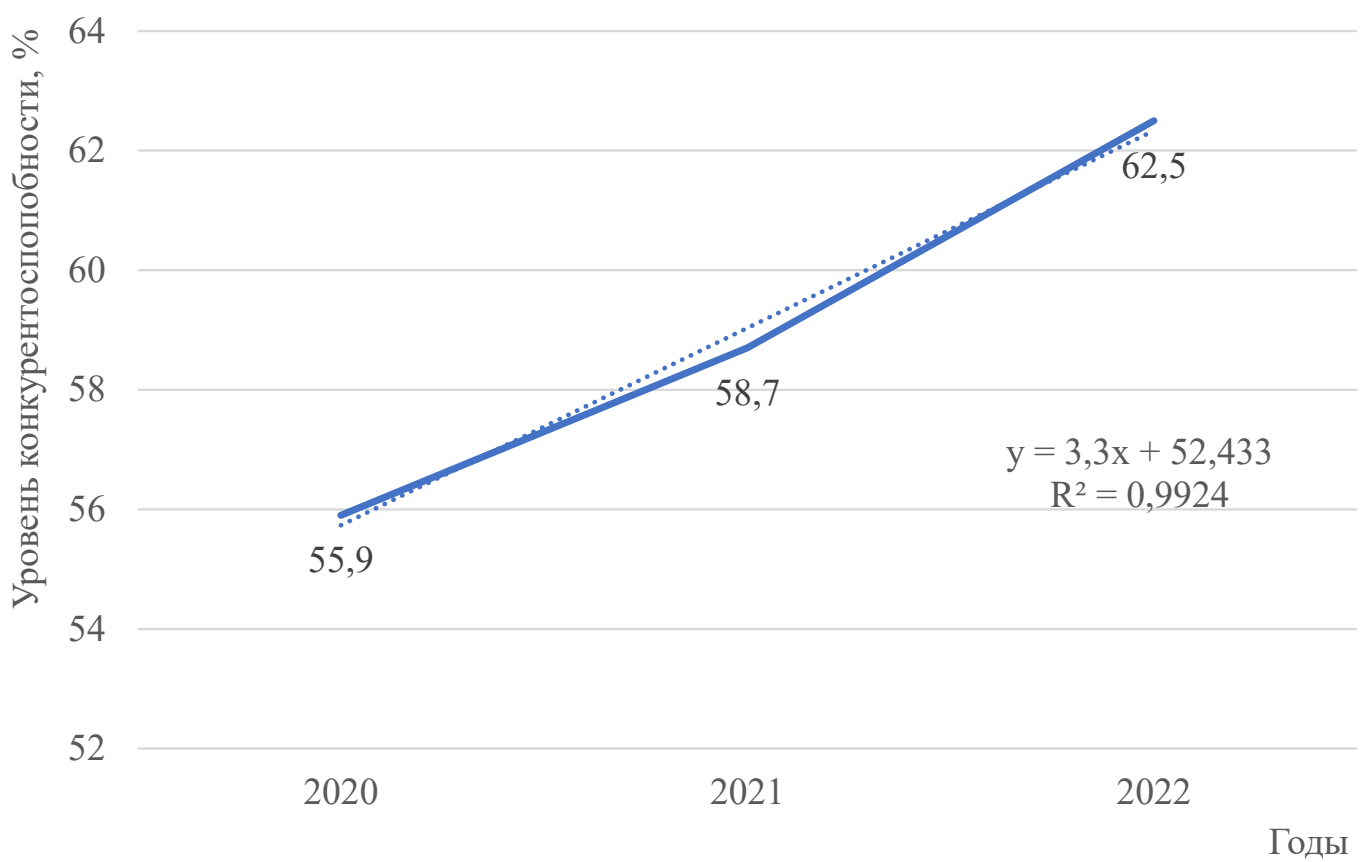

Puc. 2. Возможные варианты уровня конкурентоспособности высших учебных заведений Российской Федерации, достигнутые благодаря активизации развития виртуальной мобильности высших учебных заведений в 2020-2022 годах

способности высших учебных заведений Российской Федерации, достигнутые благодаря активизации развития виртуальной мобильности высших учебных заведений в 2020-2022 годах приведены на рисунке 2.

Таким образом, можно сделать вывод, что текущее конкурентное положение высших учебных заведений в Российской Федерации не является оптимальным и имеет ярко выраженную тенденцию к снижению, относительно пятилетнего ретроспективного периода. Основными причинами сложившейся ситуации стали повышение стоимости образовательного процесса на фоне снижения его качества и возникновения ряда проблем демографического характера на внутреннем рынке.

В целях повышения уровня конкурентоспособности высших учебных заведений Российской Федерации на ближайшие три года, по мнению авторов, целесообразно активизировать развитие виртуальной мобильности учебного процесса, направленное, в том числе на: значительную замену прослушивания лекционного материала в очной форме на интерактивную; частичную замену проведения семинарских занятий в очной форме на интерактивную; частичную замену проведения контрольных точек в очной форме на интерактивную и прочее.

\section{Библиографический список}

1. Гриншкун В.В., Краснова Г.А. Виртуальные университеты: факторы успеха и перспективы развития / В.В. Гриншкун, Г.А. Краснова // Вестник Российского университета дружбы народов. Серия: Информатизация образования - Москва: Российский университет дружбы народов, 2018. - № 15._- С. 7-17.

2. Заярная И.А. Влияние кадровых рисков на конкурентоспособность ВУЗА / И.А. Заярная // Вестник алтайской академии экономики и права - Б: Изд-во: Автономная некоммерческая образовательная организация высшего образования «Алтайская академия экономики и права», г. Барнаул, 2018. - № 5._ С. $137-141$.

3. Киреева Н.С., Слепенкова Е.В. И др. Повышение конкурентоспособности вузов: международный опыт академического предпринимательства / Н.С. Киреева, Е.В. Слепенкова, Т.С. Шипунова, Р.А. Искандарян // Russian journal of entrepreneurship - Москва: Изд-во «Креативная экономика», 2017._№ 20.- С. $2910-2922$. 
4. Сидорова Е. Е., Циликова М.С. и др. Экономические аспекты корпоративной интеграции подразделений высшего учебного заведения в целях повышения качества образовательного процесса / М.С. Циликова, Е.Е. Сидорова, И.В. Аввакумова, Д.А. Прусакова // Экономические науки - Москва: Изд-во ООО «24-Принт», 2018. - № 10.- С. 75-79.

5. Сухорукова Д.В. Конкурентоспособность российских вузов [Электронный ресурс] // Международный студенческий научный вестник. Электронный научный журнал, 2017. - № 3 (https:/eduherald.ru/pdf/2017/3/17178. pdf)

6. Тимошенко Л. П., Циликова М. С., Аввакумова И.В. Анализ банковского сектора РФ и финансовых институтов (банков), оперирующих в нем / Л.П. Тимошенко, М.С. Циликова, И.В. Аввакумова // Азимут научных исследований: экономика и управление - Тольятти: Изд-во «Некоммерческое Партнерство «Институт направленного образования», 2019.- № 1.- С. 321-325.

7. Nawaz, D., \& Gomes, A. (2014). Review of Knowledge Management in Higher Education Institutions. European Journal of Business and Management, pp. 71-79.

8. Vidaver-Cohen, D. (2007). Reputation Beyond the Rankings: A Conceptual Framework for Business School Research. Palgrave Macmillan Ltd, pp. 278-304.

9. Компания «Ernst\&Young» [Электронный ресурс]: аналитические материалы - Официальный сайт рейтингового агентства «Ernst\&Young», 2019.- Режим доступа: https://www.ey.com/ru

10. Рейтинговое агентство «Эксперт РА» [Электронный ресурс]: аналитические материалы - Официальный сайт рейтингового агентства «Эксперт РА», 2019.- Режим доступа: https://raexpert.ru 